\title{
BMJ Open Community-linked maternal death review (CLMDR) to measure and prevent maternal mortality: a pilot study in rural Malawi
}

\author{
Olivia Bayley, ${ }^{1}$ Hilda Chapota, ${ }^{2}$ Esther Kainja, ${ }^{2}$ Tambosi Phiri, ${ }^{2}$ \\ Chelmsford Gondwe, ${ }^{3}$ Carina King, ${ }^{1}$ Bejoy Nambiar, ${ }^{1}$ Charles Mwansambo, ${ }^{4,5}$ \\ Peter Kazembe, ${ }^{5,6}$ Anthony Costello, ${ }^{1}$ Mikey Rosato, ${ }^{7}$ Tim Colbourn ${ }^{1}$
}

To cite: Bayley 0 , Chapota $\mathrm{H}$, Kainja $\mathrm{E}$, et al. Communitylinked maternal death review (CLMDR) to measure and prevent maternal mortality: a pilot study in rural Malawi. BMJ Open 2015;5:e007753. doi:10.1136/bmjopen-2015007753

- Prepublication history and additional material is available. To view please visit the journal (http://dx.doi.org/ 10.1136/bmjopen-2015007753).

Received 22 January 2015 Revised 12 March 2015 Accepted 27 March 2015

CrossMark

For numbered affiliations see end of article.

Correspondence to Dr Timothy Colbourn; t.colbourn@ucl.ac.uk

\section{ABSTRACT}

Background: In Malawi, maternal mortality remains high. Existing maternal death reviews fail to adequately review most deaths, or capture those that occur outside the health system. We assessed the value of community involvement to improve capture and response to community maternal deaths.

Methods: We designed and piloted a community-linked maternal death review (CLMDR) process in Mchinji District, Malawi, which partnered community and health facility stakeholders to identify and review maternal deaths and generate actions to prevent future deaths. The CLMDR process involved five stages: community verbal autopsy, community and facility review meetings, a public meeting and bimonthly reviews involving both community and facility representatives.

Results: The CLMDR process was found to be comparable to a previous research-driven surveillance system at identifying deaths in Mchinji District (population 456500 in 2008). 52 maternal deaths were identified between July 2011 and June 2012, 27 $(52 \%)$ of which would not have been identified without community involvement. Based on district estimates of population $(500000)$ and crude birth rate (35 births per 1000 population), the maternal mortality ratio was around 300 maternal deaths per 100000 live births. Of the 41 cases that started the CLMDR process, 28 $(68 \%)$ completed all five stages. We found the CLMDR process to increase the quantity of information available and to involve a wider range of stakeholders in maternal death review (MDR). The process resulted in high rates of completion of community-planned actions $(82 \%)$, and district hospital $(67 \%)$ and health centre $(65 \%)$ actions to prevent maternal deaths.

Conclusions: CLMDR is an important addition to the established forms of MDR. It shows potential as a maternal death surveillance system, and may be applicable to similar contexts with high maternal mortality.

\section{INTRODUCTION}

Around the world, many women continue to die as a result of pregnancy and childbirth.

\section{Strengths and limitations of this study}

- This pilot study in Mchinji District, central region of Malawi, shows that a community-linked maternal death review (CLMDR) process identified twice as many maternal deaths as the existing facility review process; yielded richer data; and led to more actions being taken after the review.

- Communities and health facility representatives worked in partnership to investigate and respond to maternal deaths occurring in communities and health facilities.

- Confidentiality of the death review was limited to allow participation of, gain information from, and spur action from the community. No adverse effects of this openness were reported.

- Our pilot study delineated key issues to consider for scale-up: the CLMDR process adds to existing workload especially for community health workers; was not started for some cases of death; and can take over 6 months for each case (although we believe this can be beneficial). Raising the status of the community involved is essential to ensure the sustainability of the process.

In 2013 an estimated 292982 maternal deaths occurred worldwide, ${ }^{1}$ most preventable with proven interventions. The UN Secretary General's Commission on Information and Accountability recommends the introduction of better methods to count maternal deaths and to review and monitor progress. ${ }^{2}$

Maternal death audit is an important tool to prevent maternal deaths, and uses knowledge of the circumstances of a death to help prevent future deaths. Maternal death audit covers three approaches: confidential enquiry into maternal deaths, facility-based maternal death review (MDR) and community-based data-gathering known as verbal autopsy. WHO 
defines facility-based MDR as a 'qualitative, in-depth investigation of the causes of, and circumstances surrounding maternal deaths which occur in healthcare facilities'. ${ }^{4}$ The process involves identifying cases of maternal death, collecting and analysing information regarding the contributing factors, using this information to formulate recommendations for action, and evaluating the outcomes of these actions.

The existing system in Malawi fails to adequately achieve these objectives due to weaknesses in the six key areas detailed in the Methods section below. Although the Malawi Ministry of Health does conduct nationallevel confidential enquiries into maternal deaths, they are mainly limited to the use of facility-based MDR. ${ }^{5}$ In practice, however, facility-based MDR is fraught with problems and there is no routine system for conducting community-based verbal autopsy. ${ }^{6}$ In order to address the limitations of the present system, in partnership with the Malawian Ministry of Health, we designed and piloted an alternative community-linked MDR system (CLMDR), combining the strengths of facility-based MDR and community verbal autopsy.

WHO and UNFPA recognise the value of accurate and timely investigation of maternal deaths to stimulate actions to prevent maternal deaths in future. They recommend Maternal Death Surveillance and Response (MDSR) to combine verbal autopsy with facility death review. ${ }^{78}$ The availability of community-level data for this MDSR system is currently limited in scope, so innovative methods are required to develop a sustainable model.

Our study describes the Malawian context and identifies six weaknesses of the current MDR system. We present the pilot study of the CLMDR process over a 1-year period, and the results of how it can overcome these weaknesses and provide an estimate of maternal mortality. We conclude with thoughts on the added value and applicability of the CLMDR approach.

\section{METHODS}

Location

Malawi has a high, though declining, maternal mortality ratio. ${ }^{9}$ The most recent national survey estimated 574 maternal deaths/100 000 live births during the period 2008-2014. ${ }^{10}$ The leading biological causes of maternal death in Malawi are postpartum haemorrhage, postpartum sepsis, ruptured uterus, complications of abortion, antepartum haemorrhage, pregnancy-induced hypertension, and as indirect causes anaemia and HIV/ AIDS. ${ }^{11}$ Behind each death is a complex story of social, behavioural, economic, logistical and health system factors which can be grouped into the 'three delays' model. ${ }^{12}$ A delay by the family in the decision to seek care, a delay in reaching appropriate care once the decision has been made and a delay in receiving adequate care after arriving at the health facility may all contribute to a maternal death. ${ }^{13}$ A recent study found that in Malawi, delay in receiving adequate care was the commonest delay due to referral delays, missed diagnoses, lack of blood, lack of drugs, inadequate care or severe mismanagement. ${ }^{13}$ The health system struggles with shortages of personnel with insufficient knowledge and low morale, inaccessible facilities, and irregular drug supplies. ${ }^{14} 15$

\section{Weaknesses of the current MDR system}

\section{Maternal death identification}

While a maternal death is a notifiable event in Malawi, the Ministry of Health notification system attempts to identify only those maternal deaths that occur in hospital. However, one-third of all deaths are known to occur outside health facilities, either at the woman's home, the home of a traditional healer, or in transit to a facility, and these are presently not identified by the hospital-based notification system. ${ }^{16}$

\section{Review of maternal deaths}

The Ministry of Health aims to review all maternal deaths occurring in health facilities, but in reality this is not achieved. A review of emergency obstetric care services in Malawi in 2010 found that only 89 of 309 health facilities (29\%) had conducted MDRs, and only 153 of 597 (26\%) maternal deaths recorded were included in these reviews. ${ }^{17}$ Barriers to effective MDR include missing medical charts, poor documentation and record keeping, shortage of senior staff to conduct the reviews, a fear of blame and a lack of resources, commitment and knowledge or skills for the proper conducting of reviews. ${ }^{6} 1118$ MDR is not even attempted for deaths occurring in the community where many women are either unable to access quality healthcare or avoid the formal health sector. ${ }^{19}$

\section{Quality and quantity of information available}

The outcome of an MDR process is dependent on the quality of the data gathered. Current data comes from hospital records, which often fail to adequately record patient history, examination findings, monitoring, results and management. ${ }^{18}$ In one study, less than $20 \%$ of postnatal women's charts were correctly completed. ${ }^{20}$ The lack of accurate written data may be compounded by a culture of blame that inhibits staff from sharing valuable information. ${ }^{6}$ In a context where substandard care has been found to contribute to approximately one-third $(38 \%)$ of institutional deaths, ${ }^{21}$ good quality data is essential to the MDR process.

\section{Stakeholder involvement}

Only a limited number of hospital staff are involved in the MDR process. ${ }^{22}$ Individuals such as community health workers and non-clinical staff such as pharmacists, laboratory technicians or transport coordinators whose actions may affect maternal outcomes, are not represented. ${ }^{6}$ There is no involvement of the woman's community, meaning, that her family and traditional 
leaders are unable to contribute their insights to the process or put forward ideas for action.

\section{Community mobilisation and action}

A recent study in Mchinji District, Malawi, added to the evidence that communities themselves have significant potential to reduce maternal and neonatal mortality when they are involved in planning and implementing community actions. ${ }^{23}{ }^{24}$ Failing to involve communities in MDR, therefore, fails to utilise this potential.

\section{Accountability of health workers}

When health workers plan to take action following a MDR there is no official monitoring of whether these actions are taken, as completion of the maternal death follow-up form is almost non-existent. ${ }^{6}$ There is also no forum for communities to hold health workers accountable for the actions identified to prevent future deaths. Motivation for MDR among health workers is reported to be low, while communities are highly motivated to take steps to prevent maternal deaths. ${ }^{6} 23$

We hoped that these limitations could be overcome by involving the woman's community in all stages of the process, from identifying the death, to holding review meetings and monitoring the completion of planned actions. We aimed for a blame-free process to review all maternal deaths, including those occurring in the community; supplement the limited hospital data with rich descriptive information from the community; and include a wider group of health facility staff and community representatives. We hoped that this new process would catalyse health facility and community actions to address the determinants of maternal death; improve the accountability of health workers; and, by elevating the community as partners in the process, generate a self-sustaining MDR process fuelled by community motivation to prevent maternal deaths.

\section{Design of the CLMDR process}

The CLMDR system was designed by MaiMwana, a Malawian non-governmental organisation focusing on women and children's health, University College London, UK, and Ministry of Health of Malawi staff, taking into account evidence from published work on MDR and discussions with maternal death review experts. To design the process, we drew on evidence from a number of studies that have used social autopsy to enhance maternal health programmes. In Indonesia, social autopsy and medical records were used together to review deaths, with some community involvement. ${ }^{25}$ Another programme, based in India, used communitybased maternal verbal social autopsies to generate data regarding maternal deaths, which was then shared with the community to encourage participatory development of health interventions. ${ }^{26} \mathrm{~A}$ number of studies of child deaths have also used verbal autopsy data to feed back to communities, but to a lesser degree. ${ }^{27}$
The CLMDR project was discussed with local leaders who gave their consent and input. The project was initially piloted in four of the 12 health centre catchment areas in Mchinji District. Following feedback from all participants and the Malawi national-level safe motherhood taskforce, the process was modified (shortening and combining reporting into one form) and then rolled out across the whole district for a 1-year period (July 2011-June 2012). Project staff trained 350 community teams, made up of the group village headman, community health workers (called Health Surveillance Assistants (HSA) and volunteers. Health centre teams were created at all 12 health centres providing maternity care in the district. The existing MDR team at the district hospital was expanded (to include non-health professionals-drivers, pharmacy, laboratory, support staff) and strengthened with further training on their roles and responsibilities.

\section{Overview of the CLMDR process}

The process (figure 1) was triggered in the event of any maternal death, by community CLMDR team members hearing about a death in their area. Stage 1 began with the woman's family giving consent for the process, followed by a verbal autopsy, or structured interview, including multiple open-ended free-text questions about the events leading up to her death. This form (see web appendix 1) was used to record data at all stages of the process and designed to facilitate discussion and communication between participants.

Stage 2 was a meeting held in the woman's local area by the community team. They recorded factors they believed contributed to the woman's death, and suggested strategies to prevent future deaths.

Stage 3 was a meeting held at the woman's local health facility or at the district hospital dependent on where the death occurred, with a broad spectrum of health centre staff, district hospital staff and the HSA. The HSA reported the information from the verbal autopsy and the community team discussions. Participants agreed on a medical cause of death and health facility factors that may have contributed to the death, after which they recorded the strategies that they planned to prevent future deaths. Action points were assigned to individual health centre and district hospital staff to implement.

Stage 4 was a public meeting held in the woman's local community, attended by district hospital and health centre representatives, the HSA, community leaders and community members-all were welcome to attend. The HSA sought the family's consent to summarise the case in order to facilitate an open discussion of all relevant factors. The health workers presented their planned action points. The community agreed on community factors that may have contributed to the death and planned their own strategies, assigning action points for individuals to implement. 


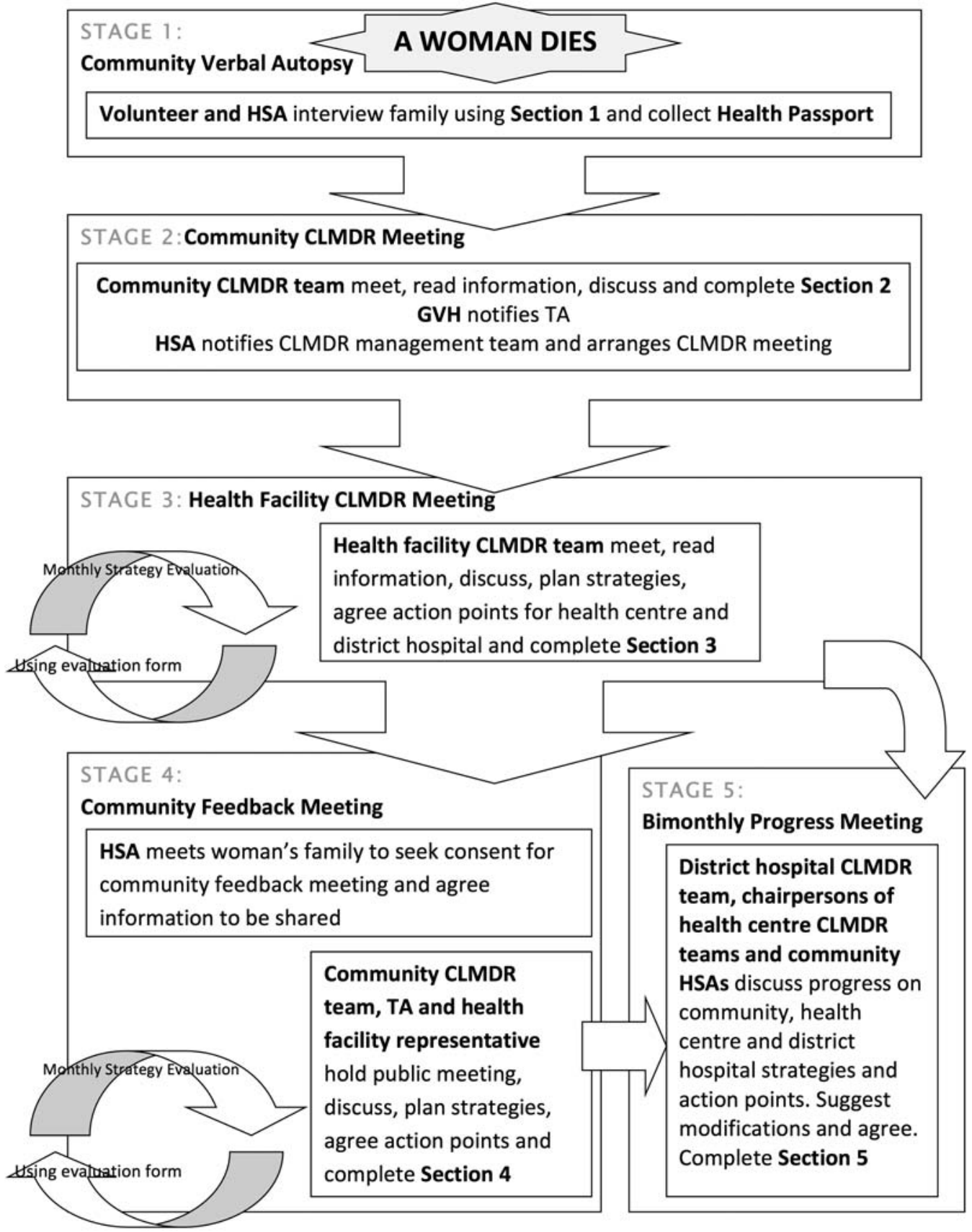

Figure 1 Flow chart of CLMDR process. CLMDR, community-linked maternal death review; GVH, group village headman; HSA, health surveillance assistant; TA, traditional authority.

Stage 5 was a bimonthly meeting, which provided an opportunity for community and health facility representatives to hear about progress on implementing action points, celebrate successes, and to identify and overcome any barriers to action. An additional meeting of traditional leaders was held quarterly in order to share innovations and lessons learned across the whole district.

\section{Sample}

Over a 1-year period, from July 2011 until June 2012, we attempted to review every maternal death of a woman resident in Mchinji District. The district population was
456500 in the 2008 census. With a growth rate of $2 \%$, the population at the time of the study was probably close to half a million. A maternal death was defined as the death of a woman while pregnant or within 42 days of termination of pregnancy, irrespective of the duration and the site of the pregnancy, from any cause related to or aggravated by the pregnancy or its management, but not from accidental or incidental causes. ${ }^{28}$ All maternal deaths of Mchinji women were included even if they died outside the district, such as at the central hospital in the capital city, Lilongwe. Women who died in the district but who were resident outside the district (ie, from 
neighbouring Zambia, Mozambique or surrounding Malawian districts) were excluded from the sample as it would be impossible to complete the CLMDR process without involvement of a community team in the woman's home village.

\section{Data collection and indicators of success}

Data collection was via the combined form (see web appendix 1), completed by either the community CLMDR team or the health facility CLMDR team at each stage of the process. Process data was collected by the research team and included information on who initiated the process, numbers of people attending the community feedback meetings, and feedback from all participants during the pilot and rollout phases of the project.

We assessed the CLMDR process against the weaknesses of the pre-existing MDR process. We measured indicators relating to each identified weakness of the existing system (table 1).

\section{Data management and analysis}

Each form was collected by the study team once the maternal death review process had been completed. A total of two forms could not be traced after completion and are therefore not included in this analysis. Descriptive statistics (counts and percentages) were produced from the quantitative data, which was analysed in Stata V.12.1 for Mac. Qualitative data was extracted (following translation of the relevant sections of the forms) and grouped into themes.

Table 1 Identified weaknesses of existing maternal death review (MDR) process and indicators used to assess community-linked maternal death review (CLMDR)

\begin{tabular}{|c|c|}
\hline Identified weakness & $\begin{array}{l}\text { Indicator used to assess } \\
\text { CLMDR }\end{array}$ \\
\hline $\begin{array}{l}\text { 1. Maternal death } \\
\text { identification }\end{array}$ & $\begin{array}{l}\text { Source of identification of } \\
\text { maternal death, that is, } \\
\text { community CLMDR team, } \\
\text { health facility CLMDR team or } \\
\text { another source }\end{array}$ \\
\hline $\begin{array}{l}\text { 2. Review of maternal } \\
\text { deaths }\end{array}$ & $\begin{array}{l}\text { Completion of each section of } \\
\text { the form indicating completion } \\
\text { of the relevant stage in the } \\
\text { process }\end{array}$ \\
\hline $\begin{array}{l}\text { 3. Quantity of } \\
\text { information available }\end{array}$ & $\begin{array}{l}\text { Availability of section } 1 \text { (verbal } \\
\text { autopsy data) at the health } \\
\text { facility CLMDR meeting }\end{array}$ \\
\hline $\begin{array}{l}\text { 4. Stakeholder } \\
\text { involvement }\end{array}$ & $\begin{array}{l}\text { Numbers of participants present } \\
\text { at each stage of the CLMDR } \\
\text { process and breakdown }\end{array}$ \\
\hline $\begin{array}{l}\text { 5. Community } \\
\text { mobilisation and action }\end{array}$ & $\begin{array}{l}\text { Planned action points and rates } \\
\text { of completion of action points }\end{array}$ \\
\hline $\begin{array}{l}\text { 6. Accountability of } \\
\text { health workers }\end{array}$ & $\begin{array}{l}\text { Planned action points and rates } \\
\text { of completion of action points }\end{array}$ \\
\hline
\end{tabular}

\section{Ethics}

Confidentiality is a norm of MDRs, enforced in order to improve the accuracy of reporting events, to protect the confidentiality of the deceased woman and her family, and to protect health workers from blame and recriminations resulting from the publication of their actions. The potential negatives of a more open process were carefully considered during the design phase. On balance, we hoped that the motivation of a community affected by a death would be one of the drivers of the process. The community required some details of the case in order to draw meaningful conclusions and generate relevant actions. Family consent (both written and verbal) was an absolute pre-requisite of the CLMDR process and this was also sought again formally prior to the public community feedback meeting. It could also be withdrawn at any stage. The HSA publicised only the summary of the case that had been previously agreed with the family prior to the meeting. All other discussions were confidential and this was reinforced in training and at the beginning of each meeting using a standardised text read out by the chairperson.

We recognised that discussion of a maternal death can result in blame and recriminations. In order to avoid this, the blame-free nature of the process was emphasised during training and was reiterated at the beginning of each meeting using standardised text on the form (see web appendix 1).

\section{RESULTS}

\section{Maternal death identification}

The CLMDR process increased the number of maternal deaths identified compared to the Ministry of Health notification system alone. During the study year, 52 maternal deaths were identified. Of these, 25 maternal deaths $(48 \%)$ were identified by the existing notification system at the district hospital. A total of 43 maternal deaths (83\%) were identified by community CLMDR teams. Of note, this included four deaths that occurred at the district hospital, which had been overlooked by the hospital system.

In addition to the community and health facility CLMDR teams identifying deaths, a further death was identified through a radio broadcast about deaths of transient workers on a tobacco estate. The process also identified four deaths of women who lived outside the district. These were excluded from the study as having no community maternal death review team covering their home village meant they could not undergo the full process.

The study findings give an estimate of the maternal mortality ratio: 52 deaths from a population of 500000 and a crude birth rate of 35 births per 1000 population results in a ratio of around 300 maternal deaths per 100000 live births. The national crude birth rate from the 2008 census was $39.5,{ }^{29}$ but we allowed for a secular fall. 


\section{Review of maternal deaths}

The CLMDR process resulted in an increase in maternal deaths being subject to review, including those deaths that occurred outside the district hospital. Overall, of the 52 maternal deaths, $45(86 \%)$ were subject to some form of review; $37(71 \%)$ were discussed at a community CLMDR meeting, $44(85 \%)$ were discussed at a health facility CLMDR meeting, $32(62 \%)$ were discussed at a community feedback meeting, and $35(67 \%)$ were discussed at a bimonthly review meeting. Of the 41 maternal deaths that started the CLMDR process, 28 cases (68\%) completed all five stages. Non-completion of one or more stages was due to family declining community feedback meeting in five cases; community CLMDR meeting not occurring in three cases; HSA failing to organise a meeting in two cases; the form being lost in two cases; and death outside the district preventing health facility MDR meeting in one case.

Of the 11 cases that did not start the process, in 8 cases it was not possible to trace the woman's next of kin (in 5 cases she was a transient worker or her family moved away following the death); in 2 cases the family declined consent to start the process; and in 1 case no details were known about the woman's death, which occurred outside the district. Nonetheless, of these 11 cases, 5 still underwent a health facility CLMDR meeting.

From the date of the maternal death, there were, on average, 76 days to the community CLMDR meeting, 141 days to the health facility CLMDR meeting, 174 days to the community feedback meeting, and 231 days to the bimonthly review meeting (see web appendix 2 ).

\section{Quantity of information}

The verbal autopsy form was available in 39 of the 44 cases that were discussed at health facility CLMDR meetings during the study period. The form contained a minimum of closed questions (which are more difficult to share in a meeting context) and used open-ended, free-text questions, which described events and invited discussion of factors that may have delayed her decision to seek care, or reach care, as well as delays in receiving care. Such factors included disrespectful treatment by health workers, being turned away from health centres, misdiagnoses, slow referral pathways, lack of hospital transport and unavailability of life-saving treatments. This generated a more informed process, which participants found more satisfactory than using hospital records alone. For example, a midwife in charge of one of the health centres said:

Using information from the deceased family together with hospital records during reviews assists to come up with a root cause of the problem which enables us to come up with real contributing factor and good strategies

and a supervisor of community health workers said:

detailed verbal autopsy gives a true picture of what happened and generates discussion with communities and health facility personnel.

\section{Stakeholder involvement}

The CLMDR process significantly increased the number of people involved in MDR activities. Over the course of the year, the CLMDR process involved a total of 3166 participants (although many may have attended more than one meeting). Numbers of attendees were not recorded for all meetings, but where data was recorded, on average, community CLMDR meetings were attended by 10 people (a total of 376 people), health facility CLMDR meetings were attended by 11 people (a total of 356 people), and community feedback meetings were attended by 98 people (a total of 2434 people; table 2). Community feedback meeting participants represented a broad spectrum of the community, with women making up 53\%, men $35 \%$, young people $6 \%$, and traditional leaders, health workers and MaiMwana staff making up the remaining $6 \%$.

\section{Community mobilisation and action}

In addition to drawing large crowds to discussions about each maternal death, the CLMDR process resulted in concrete community actions to improve maternal health. Action points included: community meetings to explore traditional beliefs; instituting bye-laws to prevent traditions posing a risk to pregnant women; educating men on their roles and responsibilities in supporting women during pregnancy, delivery and the postpartum period; lobbying the health facility advisory committee for more respectful treatment of women during antenatal care and delivery; establishing a mobile antenatal clinic; mobilising community funds for bicycle ambulance maintenance; establishing a youth club, and organising young female counsellors to support pregnant women.

Where data was recorded (in 25 cases of the 32 completing stage 4), on average 2.2 action points (range 14) were made per community feedback meeting, and 1.8 action points (range $0-4$ ) were reported completed; $82 \%$ of all proposed community action points were reported completed, and in $84 \%$ of cases at least one action point was reported completed.

\section{Accountability of health workers}

During the community feedback meetings, health workers presented their planned actions to the community. At the bimonthly meetings, community representatives could question them about whether their planned actions had been successfully completed. Action points included designing a new antenatal form to better capture risk factors, improving drug supplies to ensure adequate stocks of antihypertensive drugs, training sessions for clinicians following maternal deaths, health education events for communities on maternal health topics, improved provision of emergency transport, including a motorcycle ambulance, increased fuel allowance and changing protocols to improve access to rural hospitals.

Where action points were recorded for the health centre (in 13 of 44 cases), on average, 2.4 action points 
Table 2 Participants at community-linked maternal death review (CLMDR) meetings

\begin{tabular}{|c|c|c|c|}
\hline & $\begin{array}{l}\text { Number of meetings } \\
\text { with data }\end{array}$ & $\begin{array}{l}\text { Total } \\
\text { participants }\end{array}$ & $\begin{array}{l}\text { Average participants } \\
\text { per meeting* (range) }\end{array}$ \\
\hline \multicolumn{4}{|l|}{ Community CLMDR meeting participants } \\
\hline Community members & 37 & 195 & $5(1-7)$ \\
\hline Group village headman & 34 & 34 & $1(1-1)$ \\
\hline Community health workers $†$ & 34 & 83 & $2(1-4)$ \\
\hline Volunteers & 32 & 64 & $2(1-4)$ \\
\hline Total & & 376 & $10(8-14)$ \\
\hline \multicolumn{4}{|l|}{ Health facility CLMDR meeting participants } \\
\hline Health facility staff & 34 & 258 & $8(1-13)$ \\
\hline Health facility in-charge & 34 & 33 & $1(0-1)$ \\
\hline Community health workers $†$ & 33 & 32 & $1(0-1)$ \\
\hline Mchinji District hospital representative & 33 & 33 & $1(1-1)$ \\
\hline Total & & 356 & $11(5-16)$ \\
\hline \multicolumn{4}{|l|}{ Community feedback meeting participants } \\
\hline Traditional authority & 22 & 3 & $0(0-1)$ \\
\hline Group village headman & 24 & 21 & $1(0-1)$ \\
\hline Community health workers $†$ & 25 & 25 & $1(1-1)$ \\
\hline Health facility representative & 26 & 26 & $1(1-1)$ \\
\hline Mchinji District hospital representative & 25 & 24 & $1(0-1)$ \\
\hline MaiMwana representative & 21 & 21 & $1(1-1)$ \\
\hline Other very important people & 17 & 16 & $1(0-1)$ \\
\hline Women & 25 & 1283 & $51(14-260)$ \\
\hline Men & 25 & 860 & $34(8-200)$ \\
\hline Young people & 23 & 155 & $7(0-40)$ \\
\hline Total & & 2434 & $98(40-271)$ \\
\hline
\end{tabular}

(range 1-4) were made per meeting and 1.5 (range $0-3$ ) were completed. At health centre level $65 \%$ of all action points was reported completed, and in $77 \%$ of cases, at least one action point was reported completed. Where action points were recorded for the district hospital (in 26 of 44 cases) on average, 2.2 action points (range 1-4) per meeting were made, and 1.5 (range $0-3$ ) were completed. At district hospital level, $67 \%$ of all action points were reported completed, and in $73 \%$ of cases at least one action point was reported completed.

\section{DISCUSSION}

Our study showed that the CLMDR process improved the identification of maternal deaths compared to the national reporting system, and provided a good estimate of the maternal mortality ratio. Our estimated maternal mortality ratio of 300 maternal deaths per 100000 is close to the findings of a trial conducted in the district in which the last reported value was 328 per 100000 (21/6408 births) collected from prospective surveillance during 2009. ${ }^{23}$ Of note, community teams succeeded in identifying maternal deaths overlooked by hospital staff, as well as deaths occurring outside the health sector and outside the district. Unlike community-based surveillance systems which struggle to maintain the motivation of key informants without incentives, the CLMDR process is driven by intrinsic community motivation to prevent maternal deaths. The community is elevated from passive 'data collectors' to active partners in maternal death surveillance and response, thereby generating a potentially self-sustaining source of maternal death data.

The CLMDR process doubled the number of maternal deaths being reviewed, with $86 \%$ of identified maternal deaths being reviewed. Supplementing health facility records with verbal autopsy data significantly improved the quality of MDR discussions by exposing delays in seeking and reaching care as well as providing an alternative perspective on care received. These important insights from the community prevented health workers from jumping to simple conclusions about the reasons women died, such as blaming the woman for not presenting to a health facility sooner, and fuelled valuable discussions about quality of care. They also generated awareness of how negative experiences of healthcare affect care-seeking behaviours. Each health facility CLMDR resulted in the assignment of a medical cause of death. While it is recognised that health workers may not be as accurate as expert analysis, it is known that the accuracy of facility-assigned cause of death may be improved by using verbal autopsy data in addition to hospital records. ${ }^{18}$ An accurate stream of data on medical cause of death is essential for health services to monitor changing patterns of mortality and response to health interventions. The CLMDR process, therefore, 
provides improved data for evidence-based decision making at district and national levels. Data was not gathered at monthly strategy evaluation meetings, so the value of this aspect of the process remains unknown. These monthly evaluations may, in fact, be superseded by the bimonthly meetings attended by both community and facility representatives.

CLMDR involves large numbers of participants in discussions around maternal health and problem solving, which resulted in creative solutions and high rates of completion of planned activities. While we cannot postulate any effect on maternal death rates, when communities are empowered to identify maternal health problems and implement their own solutions to these problems, there can be significant reductions in maternal deaths. ${ }^{23}{ }^{24}$ By harnessing community capacity, the CLMDR process might contribute to reductions in maternal deaths over time.

The process aimed to improve health workers motivation and accountability to the community they serve. We believe that publicising their plans at the community feedback meetings and reporting on the outcomes of their activities at bimonthly meetings may have increased health workers' motivation to fulfil their commitments. Community participants reported improved trust in the health system, with potential benefits for uptake of available healthcare. The CLMDR process created a forum for health workers and communities to discuss the challenges they face in relation to maternal health. Traditionally, health workers occupy an elevated status in Malawi. By contrast, patients have limited power, with little choice and poor recourse in the event of inadequate treatment. By deepening understanding and creating partnerships between health workers and the communities they serve, CLMDR challenges the existing power hierarchy and contributes to a positive cultural change in patient-provider relationships.

\section{Issues for scale-up of CLIMDR}

Box 1 describes how the process is being rolled out across Malawi. Piloting the process raised the following issues to be considered for scale-up.

While we propose this system as an alternative to the existing MDR system, we recognise it may strain already limited resources, especially in high maternal mortality settings. CLMDR can result in double the number of deaths being reviewed, and requires increased staff attendance at health facility CLMDR meetings. Additionally, a senior health worker is required to attend community feedback meetings and bimonthly reviews. We experienced good attendance at CLMDR meetings. It is not known whether this would be sustained if the process was adopted into routine practice. We believe that the CLMDR process is a valuable use of staff time, and that it may reduce workload by potentially preventing serious morbidity and mortality in the long term. The process particularly relies on community health workers, who have a lot of other responsibilities, to link the health service and the community. Where HSAs failed to identify families or organise meetings, the process failed. Scale-up should consider intensified training for all HSAs. The process is lengthy, but this may maintain attention to the issues raised by the death and allow sufficient time to organise and take actions. Nonetheless, it should remain short enough to maintain commitment and motivation.

Box 1 Timeline of events following the community-linked maternal death review (CLMDR) pilot study

14 August 2012-UNFPA consultants from Uganda and Malawian Reproductive Health Unit (RHU) Ministry of Health staff discuss the CLMDR model for adoption into Malawi's Maternal Death Surveillance and Response (MDSR) system. They visit MaiMwana Project and the Mchinji District health office to learn about CLMDR.

December 2012-stakeholder meetings, lobbying by the district health officer and community leaders for continuation of CLMDR through incorporation into the annual costed district implementation plan.

April 2013-Malawian Ministry of Health and UNFPA hold MDSR briefing in Lilongwe for maternal health stakeholders to review the CLMDR model, which is presented by MaiMwana, with a view to incorporating it into the MDSR system. CLMDR data collection tools were reviewed and most of their aspects were adopted to be included in the MDSR tool.

30 September to 3 October 2013-MaiMwana participate in a capacity-building workshop held by RHU in Blantyre to present CLMDR to stakeholders in maternal health including UNFPA health officers from all five health zones (groups of districts) in Malawi, UNICEF, Save the Children, College of Medicine, MCHIP.

11 October 2013-National dissemination to Malawian Ministry of Health and maternal, newborn and child health organisations and stakeholders. Held in Lilongwe as part of dissemination of the results of trials of MaiMwana women's group and infant feeding interventions.

5 to 9 November 2013-MaiMwana involved in development of the MDSR verbal autopsy tool in a workshop organised by the Malawian Reproductive Health Directorate (formerly RHU), Ministry of Health and UNFPA. Malawian Ministry of Health adopt MaiMwana CLMDR verbal autopsy tools to be used in MDSR. June 2014-Capacity-building workshop held in Lilongwe for partners showing interest in CLMDR and MDSR.

July 2014-Evidence for Action (E4A), a pan-African project funded by the UK government, support the Malawian Ministry of Health in Salima district and engage MaiMwana and Mchinji District health office to finalise tools for verbal autopsy and a training manual for verbal autopsy use in MDSR in Salima.

September 2014-Training of trainers for implementing CLMDR as part of MDSR in the six districts of Malawi where E4A operates, and five districts of Malawi where UNFPA operates.

October to December 2014-Training and revamping of CLMDR teams in two Traditional Authorities in Mchinji District to act as beacons from which other organisations can learn about the CLMDR process. Other organisations and projects seeking to support CLMDR and MDSR in the remaining of Malawi's 28 districts include Concern Worldwide and MCHIP. 
To enable participation of the community in the process, we accepted a reduced level of confidentiality compared with traditional MDR. While this was essential and no known adverse events occurred, we recognise the potential risk of information being shared beyond the intended audience. We recognise that public discussion of health workers' actions could prevent disclosure or result in recriminations. We believe that emphasising the blame-free culture of the process was sufficient to avoid this in our pilot study, but these issues should be carefully considered with reference to each cultural context where CLMDR is introduced. A single datacollection form travelling between the community and the health facility had benefits for communication but raised the risk of information being lost or confidentiality being breached. The CLMDR management team making a copy of the form at each stage might help to mitigate this risk.

While CLMDR dramatically improved identification of deaths, the process may struggle to identify or follow-up maternal deaths of transient workers due to the reduced coverage of community teams in transient communities (eg, tobacco estates). Transient tenant farmers may have little social support and may be more vulnerable to maternal death, so efforts to improve identification and follow-up of these deaths would be worthwhile. In at least three of the seven cases where consent was declined or withdrawn, abortion or HIV contributed to the woman's death, so it seems the CLMDR process was not always able to facilitate the discussion of these sensitive topics. It is important that regardless of family consent, all identified deaths should undergo at least a confidential health facility MDR. Women dying outside the district prevented the process from being completed during the pilot study, however, rolling out CLMDR across neighbouring districts would potentially enable completion of the process regardless of place of death.

The CLMDR process attempts to challenge the existing power imbalance between health workers and the communities they serve. Project staff noted that even though a community might be highly motivated to pursue the process, where the HSA failed or the health facility was slow to organise a meeting, the community had little recourse to push it forward. Any rollout of CLMDR should try to elevate the status of the community and hold all stakeholders to account, perhaps through written agreements or parallel advocacy activities. The traditional authority (or chief) rarely attended community feedback meetings, instead being represented by a Group Village Headman. Raising traditional authority involvement from the beginning might be an effective strategy to improve the sustainability of the process in the long term.

\section{Conclusion}

CLMDR is a new and effective method of maternal death audit. By harnessing the motivation of communities to prevent maternal deaths, CLMDR improves identification and review of deaths, improves the quality of MDR meetings, provides opportunities for education on maternal health, and stimulates action in communities and health facilities. The potential of CLMDR has been recognised by the Malawi Ministry of Health who have begun a nationwide rollout. CLMDR is relevant to similar settings with high maternal mortality and needs further assessment.

\section{Author affiliations}

${ }^{1}$ University College London Institute for Global Health, London, UK ${ }^{2}$ MaiMwana Project, Mchinji, Malawi

${ }^{3}$ Department of Safe Motherhood, Mchinji District Health Management Team, Mchinji, Malawi

${ }^{4}$ Government of Malawi Ministry of Health, Lilongwe, Malawi

${ }^{5}$ Parent and Child Health Initiative (PACHI), Lilongwe, Malawi

${ }^{6}$ Baylor College of Medicine Children's Foundation, Lilongwe, Malawi

${ }^{7}$ Women and Children First, London, UK

\section{Twitter Follow Timothy Colbourn at @timcolbourn}

Acknowledgements The authors thank all the community and health facility participants of the CLMDR process and hope they found it valuable. They also thank all staff at MaiMwana Project who helped with the logistics and management of the project.

Contributors $\mathrm{OB}$ and $\mathrm{HC}$ conceived the study, which was further developed by EK, TP, MR and CG. OB, HC, EK, TP and CG were involved in data collection. TC and $\mathrm{OB}$ analysed the quantitative data. $\mathrm{HC}, \mathrm{MR}$ and $\mathrm{OB}$ analysed the qualitative data. $\mathrm{OB}$ wrote the first draft of the paper with significant input from MR and TC. All authors reviewed and revised the paper and approved the final version of the paper.

Funding This study was funded by a grant from Engender Health, no.: GMH-103-01.

\section{Competing interests None declared.}

Ethics approval This study was approved by the National Health Sciences Research Committee of Malawi, protocol 785.

Provenance and peer review Not commissioned; externally peer reviewed.

Data sharing statement No additional unpublished data is available.

Open Access This is an Open Access article distributed in accordance with the Creative Commons Attribution Non Commercial (CC BY-NC 4.0) license, which permits others to distribute, remix, adapt, build upon this work noncommercially, and license their derivative works on different terms, provided the original work is properly cited and the use is non-commercial. See: http:// creativecommons.org/licenses/by-nc/4.0/

\section{REFERENCES}

1. Kassebaum NJ, Bertozzi-Villa A, Coggeshall MS, et al. Global, regional, and national levels and causes of maternal mortality during 1990-2013: a systematic analysis for the Global Burden of Disease Study 2013. Lancet 2014;384:980-1004.

2. WHO. Keeping promises, measuring results. Commission on information and accountability for women's and children's health. Geneva: World Health Organization, 2011.

3. Lewis $\mathrm{G}$. Beyond the numbers: reviewing maternal deaths and complications to make pregnancy safer. Br Med Bull 2003;67:27-37.

4. Lewis G. Reviewing maternal deaths to make pregnancy safer. Best Pract Res Clin Obstet Gynaecol 2008;22:447-63.

5. Mataya R, Malawi National Confidential Committee on enquiry into maternal death. Report on the Confidential Enquiry into Maternal Deaths in Malawi (2008-2012). Lilongwe, Malawi: Reproductive Health Unit, Ministry of Health, 2013.

6. Kongnyuy EJ, van den Broek N. The difficulties of conducting maternal death reviews in Malawi. BMC Pregnancy Childbirth 2008;8:42.

7. Danel I, Graham WJ, Boerma T. Maternal death surveillance and response. Bull World Health Organ 2011;89:779-9A. 
8. Hounton S, De Bernis L, Hussein J, et al. Towards elimination of maternal deaths: maternal deaths surveillance and response. Reprod Health 2013;10:1.

9. Colbourn T, Lewycka S, Nambiar B, et al. Maternal mortality in Malawi, 1977-2012. BMJ Open 2013;3:e004150.

10. National Statistical Office [Malawi]. Malawi MDG Endline Survey 2014, Key Findings. Zomba, Malawi: National Statistical Office, 2014. http://www.nsomalawi.mw/images/stories/data_on_line/ demography/MDGEndline/MalawiMDG EndlineSurveyKeyFindings Report.pdf (accessed 17 Dec 2014).

11. Kongnyuy EJ, Mlava G, van den BN. Facility-based maternal death review in three districts in the central region of Malawi an analysis of causes and characteristics of maternal deaths. Womens Health Issues 2009;19:14-20.

12. Thaddeus $\mathrm{S}$, Maine D. Too far to walk: maternal mortality in context. Soc Sci Med 1994;38:1091-110.

13. Combs Thorsen V, Sundby J, Malata A. Piecing together the maternal death puzzle through narratives: the three delays model revisited. PLoS One 2012;7:e52090.

14. Bayley O, Colbourn T, Nambiar B, et al. Knowledge and perceptions of quality of obstetric and newborn care of local health providers: a cross-sectional study in three districts in Malawi. Malawi Med J 2013;25:110-13.

15. Mueller $\mathrm{DH}$, Lungu $\mathrm{D}$, Acharya $\mathrm{A}$, et al. Constraints to implementing the Essential Health Package in Malawi. PLoS ONE 2011; 6:e20741.

16. Colbourn T, Nambiar B, Costello A. MaiKhanda-final evaluation report. The impact of quality improvement at health facilities and community mobilisation by women's groups on birth outcomes: an effectiveness study in three districts of Malawi. London: The Health Foundation, 2013:1-364. http://www.health.org.uk/publications/ maikhanda/ (accessed 11 Mar 2015).

17. Republic of Malawi Ministry of Health. Malawi 2010 EmONC needs assessment final report. 2010

18. Combs Thorsen V, Sundby J, Meguid T, et al. Easier said than done!: methodological challenges with conducting maternal death review research in Malawi. BMC Med Res Methodol 2014;14:29.
19. Yoder PS, Rosato M, Riad M, et al. Women's recall of delivery and neonatal care: a study of terms, concepts and survey questions. Calverton, Maryland, USA: Macro International, 2010.

20. Ashwood-Smith H, Simpson H. An observational study of obstetric care quality in Southern Malawi. Malawi Safe Motherhood Report, 2003.

21. Ratsma E, Lungu K, Hofman J, et al. Why more mothers die: confidential enquiries into institutional maternal deaths in the Southern Region of Malawi. Malawi Med J 2005;17:75-80.

22. Vink NM, de Jonge HCC, Ter Haar R, et al. Maternal death reviews at a rural hospital in Malawi. Int J Gynaecol Obstet 2013;120:74-7.

23. Lewycka S, Mwansambo C, Rosato M, et al. Effect of women's groups and volunteer peer counsellors on rates of mortality, morbidity and health behaviours in mothers and children in rural Malawi (MaiMwana): a factorial, cluster-randomised controlled trial. Lancet 2013;381:1721-35.

24. Prost A, Colbourn T, Seward N, et al. Women's groups practising participatory learning and action to improve maternal and newborn health in resource-limited settings: systematic review and meta-analysis. Lancet 2013;381:1736-46.

25. Supratikto G, Wirth ME, Achadi E, et al. A district-based audit of the causes and circumstances of maternal deaths in South Kalimantan, Indonesia. Bull World Health Organ 2002;80:228-35.

26. UNICEF. Maternal and perinatal death inquiry and response: empowering communities to avert maternal deaths in India. New Delhi: UNICEF, 2008. http://www.unicef.org/india/MAPEDIRMaternal_and_Perinatal_Death_Inquiry_and_Response-India.pdf (accessed 17 Dec 2014).

27. Kalter HD, Salgado R, Babille M, et al. Social autopsy for maternal and child deaths: a comprehensive literature review to examine the concept and the development of the method. Popul Health Metr 2011;9:45.

28. WHO. International statistical classification of diseases and related health problems. 10th revision. Vol. 2. Instruction manual. 2010 edition. Geneva: World Health Organization, 2010:134.

29. National Statistical Office [Malawi]. Census of Malawi 2008. Main Report. Lilongwe, Malawi: National Statistical Office, Government of Malawi, 2010. 